\title{
The connection between cognitive development and specific fears and worries in normal children and children with below average intellectual abilities: $A$ preliminary study
}

Citation for published version (APA):

Muris, P. E. H. M., Merckelbach, H. L. G. J., \& Luijten, M. (2002). The connection between cognitive development and specific fears and worries in normal children and children with below average intellectual abilities: A preliminary study. Behaviour Research and Therapy, 40(1), 37-56. https://doi.org/10.1016/S0005-7967(00)00115-7

Document status and date:

Published: 01/01/2002

DOI:

10.1016/S0005-7967(00)00115-7

Document Version:

Publisher's PDF, also known as Version of record

Please check the document version of this publication:

- A submitted manuscript is the version of the article upon submission and before peer-review. There can be important differences between the submitted version and the official published version of record. People interested in the research are advised to contact the author for the final version of the publication, or visit the DOI to the publisher's website.

- The final author version and the galley proof are versions of the publication after peer review.

- The final published version features the final layout of the paper including the volume, issue and page numbers.

Link to publication

\footnotetext{
General rights rights.

- You may freely distribute the URL identifying the publication in the public portal. please follow below link for the End User Agreement:

www.umlib.nl/taverne-license

Take down policy

If you believe that this document breaches copyright please contact us at:

repository@maastrichtuniversity.nl

providing details and we will investigate your claim.
}

Copyright and moral rights for the publications made accessible in the public portal are retained by the authors and/or other copyright owners and it is a condition of accessing publications that users recognise and abide by the legal requirements associated with these

- Users may download and print one copy of any publication from the public portal for the purpose of private study or research.

- You may not further distribute the material or use it for any profit-making activity or commercial gain

If the publication is distributed under the terms of Article $25 \mathrm{fa}$ of the Dutch Copyright Act, indicated by the "Taverne" license above,

Download date: 26 Apr. 2023 


\title{
The connection between cognitive development and specific fears and worries in normal children and children with below-average intellectual abilities: a preliminary study
}

\author{
Peter Muris ${ }^{\mathrm{a}, *}$, Harald Merckelbach ${ }^{\mathrm{b}}$, Monique Luijten ${ }^{\mathrm{b}}$ \\ a Department of Medical, Clinical, and Experimental Psychology, Maastricht University, P.O. Box 616, 6200 MD \\ Maastricht, The Netherlands \\ ${ }^{\mathrm{b}}$ Department of Psychology, Maastricht University, Maastricht, The Netherlands
}

Accepted 10 December 2000

\begin{abstract}
The present study explored the relationship between cognitive development and anxiety phenomena in 4-12-year-old children. Fears and worries of normal children $(n=176)$ were compared to those of children with below-average intellectual abilities (children with BAIA; $n=105$ ). We evaluated to what extent level of cognitive development as indexed by a Piagetian conservation task was associated with the presence of fears and worries. While normal children and children with BAIA did not differ with regard to the content of their fears and worries, normal children more frequently reported such anxiety phenomena during the semi-structured Anxiety Interview than did children with BAIA. Furthermore, in normal children, evidence was found to suggest that level of cognitive development contributes to the experience of fears and worries. That is, anxiety phenomena were more prevalent among those children who passed a Piagetian conservation task. However, when anxiety phenomena were assessed by means of the Koala Fear Questionnaire (KFQ), a different picture emerged. KFQ data suggested that fears were less frequent in normal children and those children with BAIA who had a higher level of cognitive functioning. Apparently, the Anxiety Interview and the KFQ tap quite different aspects of anxiety. The KFQ seems to measure primitive fears that are likely to be prevalent among children with limited cognitive capacity, whereas the Anxiety Interview assesses more sophisticated anxiety phenomena that probably depend on high levels of cognitive functioning. (c) 2001 Elsevier Science Ltd. All rights reserved.
\end{abstract}

Keywords: Fears; Worries; Cognitive development; Children

\footnotetext{
* Corresponding author.

E-mail address: p.muris@dep.unimaas.nl (P. Muris).
} 


\section{Introduction}

Fear and worry are distinct anxiety phenomena. Whereas fear refers to the unpleasant feeling that arises as a response to realistic danger (Marks, 1987), worry pertains to fearful thought processes (Borkovec, Robinson, Pruzinsky, \& DePree, 1983). Thus an important difference between these two phenomena is that fear occurs when the subject is actually confronted with a dangerous stimulus or situation, whereas worry takes place in the absence of actual danger and is primarily concerned with thinking about threatening scenarios.

Research has shown that fears are quite common in children (see for a review, Craske, 1997). For example, Ollendick, King, and Frary (1989) found an average of 14 fears reported by American and Australian youths aged 7-17 years and there are good reasons to believe that this number is quite similar across different cultures (e.g., Ollendick, Yang, King, Dong, \& Akande, 1996). Most childhood fears are concerned with dangerous situations, physical harm, and/or animals (e.g., Gullone \& King, 1992; Muris, Merckelbach, \& Collaris, 1997a; Ollendick et al., 1989; Ollendick, Yule, \& Ollier, 1991; Shore \& Rapport, 1998). However, the content of childhood fears changes as a function of age, a phenomenon that Marks (1987) termed the "ontogenetic parade" of childhood fears. Germane to this issue is the classic study by Bauer (1976) who asked 4-12-year-old children to specify what they feared most. Bauer noted that $74 \%$ of the $4-6$-yearolds, $53 \%$ of the $7-9$-year-olds, but only $5 \%$ of the 10-12-year-olds reported fears of imaginary creatures such as ghosts and monsters. In contrast, only $11 \%$ of the $4-6$-year-olds, but $53 \%$ of the 7-9-year-olds, and 55\% of the 10-12-year-olds reported fears of bodily injury and physical danger. These findings were replicated by Muris, Merckelbach, Gadet, and Moulaert (2000a). Their study also demonstrated that fears are fairly common among young children (71\%), peak in middle childhood (i.e., after age 7; 87\%), and then decline as children become older (68\%).

In contrast to specific childhood fears, worry in children has not been well researched. The few studies that have been carried out indicate that worry is also a common phenomenon among children. For example, Orton (1982) found that $>70 \%$ of a large sample of primary school children reported 10 or more topics about which they worried (see for similar findings, Muris, Meesters, Merckelbach, Sermon, \& Zwakhalen, 1998a). Children usually worry about harm befalling to themselves or to significant others, school performance, and/or social issues (e.g., Muris et al., 1998a; Silverman, La Greca, \& Wasserstein, 1995; Stickler, 1996). Vasey, Crnic, and Carter (1994) examined the developmental pattern of worries in children aged 5-6, 8-9, and 11-12 years. These authors reported that worries about threats to physical well-being predominated among the 5-6-year-olds, but were less frequent among older children. In these older children, worries primarily focused on behavioural competence, social evaluation, and psychological well-being. Furthermore, Vasey et al. (1994) noted that children in the two older age groups displayed a greater variety of worries and were more able to elaborate the negative consequences of these worries compared to the 5-6-year-olds. Highly similar results were obtained in the Muris et al. (2000a) study. That study found that a considerable proportion (47\%) of young children reported to worry every now and then, but this anxiety phenomenon became clearly more prominent in children after age 7 , with a prevalence rate of almost $80 \%$.

It is plausible to assume that the above described developmental patterns of fears and worries are mediated by children's cognitive capacities (see Marks, 1987). That is, fears and worries depend on the perception and conceptualization of immediate or anticipated threat. Perception 
and conceptualization, in turn, are intimately linked to cognitive abilities (e.g., Vasey, 1993). Thus, it is likely that at relatively young ages, fears are directed at concrete and straightforward threats (e.g., loud noises, heights, loss of physical support, and separation from the mother). However, as cognitive abilities reach a certain maturational stage, specific fears will become more sophisticated. For example, at 9 months, children learn to differentiate between familiar and unfamiliar faces and, consequently, fear of strangers becomes manifest. Following this, fears of imaginary creatures occur and these are thought to be closely related to the magical thinking that is typical for pre-school children (e.g., Bauer, 1976). Fear of animals also develops in children of this age. These fears are believed to be functionally linked to the increasing mobility of the child. That is, fear of animals would have survival value at this developmental stage, as it would guard the mobile child against potential predators (Marks \& Nesse, 1994). From age 7 onwards, children are increasingly able to infer physical cause-effect relationships and to anticipate potential negative outcomes. These cognitive changes enable children to worry. They probably also broaden the range of fear-provoking stimuli and, thus, fear of blood and injury, natural events, and social encounters may develop. In more general terms, children of this age have an increased ability to conceptualize negative consequences which is likely to enhance the potential for fears and worries (e.g., Vasey \& Daleiden, 1994).

The notion that anxiety phenomena such as fears and worries are mediated by children's cognitive capacities is widely accepted (see e.g., Ollendick et al., 1991; Vasey, 1993). Yet, only a handful of studies directly addressed the link between children's cognitive capacities and their fears and worries. Most of them compared fears of mentally retarded children with those of normal children (e.g., Ramirez \& Kratochwill, 1997; Gullone, Cummins, \& King, 1996). As expected, mentally retarded children more frequently reported fears about animals and imaginary creatures than did normal children (see also Vandenberg, 1993). Surprisingly, however, these studies also consistently found that relative to normal control children, mentally retarded children report a higher frequency and intensity of fears. Thus, whereas it has been suggested that greater cognitive capacity promotes anxiety, these studies seem to indicate that reduced cognitive capacity is associated with higher anxiety levels. However, at least two points can be raised to qualify this conclusion. To begin with, the studies cited above relied on self-report scales (e.g., the Fear Survey Schedule for Children; Ollendick, 1983; Gullone \& King, 1992) to assess fears. It is important to note that by including a relatively large number of items referring to concrete fears and fears of imaginary creatures, these measures capitalize on 'early' childhood fears, which may be more relevant for mentally retarded children than for their normal counterparts. Second, the above mentioned studies were only concerned with specific fears. Plainly, worry requires a certain degree of cognitive maturation and so it is plausible that greater cognitive capacity promotes especially this type of anxiety.

In the current study, fears and worries of children with below-average intellectual abilities (children with BAIA; $n=105)$ and normal school children $(n=176)$ were assessed by means of a semi-structured interview. During the interview, pictures and simple descriptions were used to make the anxiety phenomena more understandable for the children. Previous research has shown that this method provides a useful tool for assessing fear and worry even in very young children (Muris et al., 2000a; see also Lentz, 1985; Stevenson-Hinde \& Shouldice, 1995). The recently developed Koala Fear Questionnaire (KFQ; Muris, Meesters, \& Mayer, 2000b) was used as a concurrent anxiety measure. This scale consists of 31 potentially fear-provoking stimuli and situ- 
ations that are all illustrated with pictures. Children rate the intensity of their fear of these stimuli by using a visual scale depicting Koala bears expressing various degrees of fear $(1=n o$ fear, $2=$ some fear, $3=a$ lot of fear). The pictures and the visual anxiety scale make the KFQ suitable for younger children and children with limited intellectual abilities. Prevalence, intensity, and content of fears and worries of children with BAIA and normal children (as indexed by interview and KFQ) were compared in order to examine differences in the experience of these anxiety phenomena. It was anticipated that children with a restricted cognitive capacity (i.e., children with BAIA) would less frequently experience "sophisticated" anxiety symptoms, in particular worry, compared to children with normal cognitive capacity. Furthermore, it was expected that children with BAIA would more often report fears and worries related to concrete and/or imaginary issues than normal children.

Comparing prevalence, intensity, and content of fears and worries of children with BAIA and normal children provides only circumstantial evidence for the role of cognitive capacity in the experience of these anxiety phenomena. As mentioned above, it is assumed that after the age of 7, children have an increased ability to conceptualize negative consequences, which is likely to enhance the potential for fears and worries (Vasey \& Daleiden, 1994). According to Piaget (1970), the increased cognitive capacity of children in this developmental phase amounts to a new form of thought that he dubbed "concrete operations". During the concrete operational stage that normally develops between the ages of 7-12 years, children become increasingly able to consider more than one attribute of a stimulus or situation. This could imply that children are increasingly sensitive to negative features and potential threats associated with certain stimuli and situations. One important marker for the concrete operational stage is conservation, that is, the understanding that the appearance of objects may change while their quantity or some other essential feature may remain the same. In a typical conservation task (see for a detailed description, e.g., Cole \& Cole, 1996), children are presented with two identical glass beakers containing the same amount of water. The experimenter then pours the water from one of the beakers into a third beaker that is taller and thinner. Naturally, the water level is higher in the third beaker. Following this, the experimenter asks the child, "Does the third beaker contain more water than the old beaker, does it contain the same amount, or does it contain less?" Children's answers to this question reveal whether they have mastered the principle of conservation and, thus, whether they have reached the concrete operational stage. In the present study, performance on this conservation task was employed as a crude measure of cognitive development of children with BAIA and normal children. It was expected that children with BAIA would more often fail this task than normal children. Most importantly, we predicted frequency and intensity of fears and worries to be linked to successful performance on the conservation task. More specifically, if concrete operations, indeed, enhance the anxiety potential, one would expect that children who pass the conservation task display higher levels of fears and worries than children who fail this task.

To recapitulate, the present study sought to investigate the relationship between cognitive capacity and fear and worry in children. This issue was addressed in two ways. First, fears and worries of normal children were compared to those of children with BAIA. Second, it was examined whether level of cognitive maturation was associated with the experience of fear and worry. 


\section{Method}

\subsection{Children}

One-hundred-and-five children ( 65 boys and 40 girls) who attended a special school for children with learning difficulties (MLK-school) and 176 normal children (83 boys and 93 girls) of a regular primary school participated in this study after obtaining written informed consent from their parents.

The Dutch educational system has various special schools. The so-called school for children with learning difficulties (MLK-school) aims at teaching those children who display a marked lag in their school performance. These children clearly have BAIA. In terms of the definitions provided by the American Psychiatric Association (1994), these children can be characterized as 'mild mentally retarded' or 'borderline intellectual functioning' (see Toren et al., 1978).

Participation rates of special school and regular school children were 87.5 and $70.4 \%$, respectively. Demographic characteristics of both groups are displayed in Table 1. As can be seen, mean age of the children with BAIA was 9.5 years ( $\mathrm{SD}=2.0$, range 4-12 years). Only $21.0 \%$ of these children had a middle or high socio-economic background (this statistic was based on occupational levels of both parents), while $38.1 \%$ came from divorced families. Mean IQ of the children with BAIA was 74.7 ( $\mathrm{SD}=7.9$, range 56-90). IQ scores were obtained from children's personal files and assessed by means of a variety of tests: the Wechsler Preschool and Primary Scale of Intelligence - revised (Wechsler, 1989), the Wechsler Intelligence Scale for Children - revised (Wechsler, 1974), the Leidse Diagnostische Test (Schroots \& Alphen de Veer, 1976), and the Revisie Amsterdamse Kinder Intelligentie Test (Bleichrodt, Drenth, Zaal, \& Resing, 1987) were

Table 1

Demographic characteristics of children with BAIA and normal children

\begin{tabular}{|c|c|c|c|c|}
\hline & \multicolumn{2}{|c|}{ Children with BAIA $(n=105)$} & \multicolumn{2}{|c|}{ Normal children $(n=176)$} \\
\hline & $N$ & $\%$ & $n$ & $\%$ \\
\hline \multicolumn{5}{|l|}{ Gender } \\
\hline Boys & 65 & 61.9 & 83 & 47.2 \\
\hline Girls & 40 & 38.1 & 93 & 52.8 \\
\hline \multicolumn{5}{|l|}{ Age } \\
\hline$M(\mathrm{SD})$ & & $9.5(2.0)$ & & $8.4(2.5)$ \\
\hline 4-7-year-olds & 24 & 22.9 & 64 & 36.4 \\
\hline 8-10-year-olds & 44 & 41.9 & 70 & 39.8 \\
\hline 11-13-year-olds & 37 & 35.2 & 42 & 43.9 \\
\hline \multicolumn{5}{|l|}{ Socio-economic status } \\
\hline Low & 83 & 79.0 & 35 & 19.9 \\
\hline Middle or high & 22 & 21.0 & 141 & 80.1 \\
\hline \multicolumn{5}{|l|}{ Family structure } \\
\hline Intact families & 65 & 61.9 & 160 & 90.9 \\
\hline Divorced families & 40 & 38.1 & 16 & 9.1 \\
\hline \multicolumn{5}{|l|}{$I Q$} \\
\hline$M(\mathrm{SD})$ & \multicolumn{2}{|c|}{$75.4(9.6)$} & \multicolumn{2}{|c|}{ - } \\
\hline
\end{tabular}


used in $>95 \%$ of the cases. Most IQ scores were not up-to-date but obtained during the diagnostic intake procedure (on average 3 years earlier) when children were put in the MLK-school.

Mean age of the normal control children was 8.4 years ( $\mathrm{SD}=2.5$, range $4-13$ years). Most of these children $(80.1 \%$ ) had a middle or high socio-economic background and $9.1 \%$ came from divorced families. For the normal children, no information about IQ was available. However, as their intellectual functioning was without significant problems, it is safe to assume that their IQ levels were within the normal range. Children with BAIA and normal children differed with regard to some demographic characteristics. More specifically, the group of children with BAIA included more boys than the group of normal children $\left[\chi^{2}(1)=5.7, P<0.05\right]$. Furthermore, children with BAIA were older $[t(252.8$, adjusted $\mathrm{df})=4.0, P<0.001]$, more frequently had a low socioeconomic background $\left[\chi^{2}(1)=94.5, P<0.001\right]$, and more often came from broken families $\left[\chi^{2}(1)=34.7, P<0.001\right]$ than the normal children.

\subsection{Assessment}

\subsubsection{Anxiety interview}

The interview lasted for about $10 \mathrm{~min}$ and consisted of questions about children's fears and worries. For both anxiety phenomena, the procedure was identical and involved showing the child pictures that were briefly described (see Muris et al., 2000a). As mentioned earlier, pictures and descriptions were used to make the anxiety phenomena more understandable for the younger and children with limited intellectual capacities. After presenting each picture, children were asked whether they experienced that particular anxiety phenomenon. For example, following presentation of the picture depicting fear, children were asked, "Are you scared sometimes?" Children who indicated that the anxiety phenomenon was present, were invited to provide details about the content and severity. For fears, the pertinent questions were "What are you scared of?" (content), and "How scared are you of...?" (severity). To answer the severity item, children used a visual scale depicting Koala bears that expressed various degrees of anxiety $(1=$ not scared, $2=a$ little scared, 3=very scared). Identical questions were asked to assess the prevalence, content, and severity of children's worries.

\subsection{2. $K F Q$}

This scale consists of 31 potentially fear-provoking stimuli and situations (e.g., "being hit by a car", "the dark", "thunderstorms", "frightening movie", "rats and mice", "lions", "when other children tease you", "ghosts", "a scary man who wants to kidnap you") that are illustrated with pictures. KFQ stimuli and situations are based on self-reported top intense fears among 4-12year-old children (Muris, Merckelbach, Meesters, \& Van Lier, 1997b; Muris et al., 2000a) and on items listed in the Fear Survey Schedule for Children (Ollendick, 1983). Children rate their level of anxiety to each stimulus or situation, using a visual scale depicting Koala bears that express various degrees of fear (1=no fear, 2=some fear, 3=a lot of fear). A total score can be computed by summing the ratings across all items (range 31-93). The reliability of the KFQ appears to be satisfactory: for the present KFQ data, a Cronbach's $\alpha$ of 0.90 was found. Furthermore, previous research (Muris et al., 2000b) has shown that this scale correlates in a meaningful way with concurrent measures such as the Fear Survey Schedule for Children (Ollendick, 1983) and the trait anxiety scale of the State-Trait Anxiety Inventory for Children (Spielberger, 1973). 
Thus, two types of anxiety measures were used:

1. The anxiety interview which relied on a 'free option' method, and invited children to specify what stimuli or situations they fear and what topics they worry about; and

2. the KFQ which is a standardized self-report scale assessing children's fear levels to a variety of stimuli and situations.

\subsubsection{Conservation task}

The 'conservation of liquid volume' task has already been described in some detail (cf supra) and was actually carried out in the presence of the child. The experimenter began by asking the child whether the amounts of liquids (a favorite lemonade) in the two glasses were the same. When the child did not think that this was the case, the amounts were adjusted until the child agreed that the two glasses contained exactly the same amounts. Following this, the content of one glass was poured into a third glass that was taller and thinner and the pertinent question was asked. Conservation task performance was either scored as $0=$ failed (e.g., children who said that the tall, thin glass contained more lemonade) or 1=passed (i.e., children who said that the amounts of lemonade remained the same). Interrater reliability of the conservation task was examined in an additional pilot study in which 10 normal children (aged 4-7 years) were tested. Two independent observers (both undergraduate students) classified the reaction of the children to the task as either failed or passed. Observers agreed $100 \%(\kappa=1.0)$.

\subsection{Procedure}

Children were interviewed individually in a separate room at school. All interviews were conducted by one and the same research assistant who was a graduate psychology student trained by the senior author. First, the anxiety interview was conducted, then the KFQ was administered, and, finally, the conservation task was presented to the child. For the anxiety interview, the order of the anxiety phenomena that were discussed was counterbalanced. At the end of the procedure, children received a small present in return for their participation.

\subsection{Data analysis}

The Statistical Package for Social Sciences (SPSS) was used to calculate descriptive statistics (frequencies, percentages) and to evaluate differences between children with BAIA and normal children, age groups, and gender by means of $\chi^{2}$ tests, $t$-tests, logistic and linear regression analyses.

\section{Results}

\subsection{Anxiety interview}


Table 2

Rank order of specific fears reported by children with BAIA (anxiety interview)

\begin{tabular}{|c|c|c|c|c|c|c|}
\hline & \multicolumn{2}{|c|}{ Total group $(n=105)$} & \multicolumn{2}{|c|}{ Boys $(n=65)$} & \multicolumn{2}{|c|}{ Girls $(n=40)$} \\
\hline & Frequency & $\%$ & Frequency & $\%$ & Frequency & $\%$ \\
\hline \multicolumn{7}{|l|}{ Fear } \\
\hline 1. Animals & 25 & 23.8 & 14 & 21.5 & 11 & 27.5 \\
\hline 2. Personal harm or harm to others & 9 & 8.6 & 5 & 7.7 & 4 & 10.0 \\
\hline 3. Social threats & 6 & 5.7 & 4 & 6.2 & 2 & 5.0 \\
\hline 4. Imaginary creatures & 4 & 3.8 & 0 & 0.0 & 4 & $10.0^{\mathrm{a}}$ \\
\hline 5. Environmental threats & 3 & 2.9 & 1 & 1.5 & 2 & 5.0 \\
\hline 6. Being kidnapped & 2 & 1.9 & 0 & 0.0 & 2 & 5.0 \\
\hline Burglar & 2 & 1.9 & 0 & 0.0 & 2 & 5.0 \\
\hline 7. Frightening movies & 1 & 1.0 & 1 & 1.5 & 0 & 0.0 \\
\hline Separation from parents & 1 & 1.0 & 1 & 1.5 & 0 & 0.0 \\
\hline Being punished & 1 & 1.0 & 1 & 1.5 & 0 & 0.0 \\
\hline
\end{tabular}

a Difference between boys and girls significant at $P<0.05$.

\subsubsection{Prevalence and content of fears and worries}

3.1.1.1. Children with BAIA The percentages of children with BAIA reporting fears and worries were 51.4 and $49.5 \%$, respectively. Tables 2 and 3 show the rank orders of top intense fears and worries of children with BAIA. As can be seen, the most prevalent fears concerned animals

Table 3

Rank order of worries reported by children with BAIA (anxiety interview)

\begin{tabular}{|c|c|c|c|c|c|c|}
\hline & \multicolumn{2}{|c|}{ Total group $(n=105)$} & \multicolumn{2}{|c|}{ Boys $(n=65)$} & \multicolumn{2}{|c|}{ Girls $(n=40)$} \\
\hline & Frequency & $\%$ & Frequency & $\%$ & Frequency & $\%$ \\
\hline \multicolumn{7}{|l|}{ Worry } \\
\hline 1. Personal harm or harm to others & 15 & 14.3 & 8 & 12.3 & 7 & 17.5 \\
\hline 2. Social threats & 11 & 10.5 & 6 & 9.2 & 5 & 12.5 \\
\hline 3. Separation from parents & 6 & 5.7 & 4 & 6.2 & 2 & 5.0 \\
\hline Being punished & 6 & 5.7 & 5 & 7.7 & 1 & 2.5 \\
\hline 4. Imaginary creatures & 2 & 1.9 & 2 & 3.1 & 0 & 0.0 \\
\hline Medical affairs & 2 & 1.9 & 1 & 1.5 & 1 & 2.5 \\
\hline School performance & 2 & 1.9 & 0 & 0.0 & 2 & 5.0 \\
\hline Little things & 2 & 1.9 & 2 & 3.1 & 0 & 0.0 \\
\hline 5. Animals & 1 & 1.0 & 0 & 0.0 & 1 & 2.5 \\
\hline Death & 1 & 1.0 & 1 & 1.5 & 0 & 0.0 \\
\hline Frightening movies & 1 & 1.0 & 1 & 1.5 & 0 & 0.0 \\
\hline Being kidnapped & 1 & 1.0 & 0 & 0.0 & 1 & 2.5 \\
\hline Environmental threats & 1 & 1.0 & 1 & 1.5 & 0 & 0.0 \\
\hline Divorce of parents & 1 & 1.0 & 0 & 0.0 & 1 & 2.5 \\
\hline
\end{tabular}


( $n=25,23.8 \%$, e.g., spiders, tigers, lions, crocodiles, wasps, bats), personal harm ( $n=9,8.6 \%$, e.g., accident), and social threats ( $n=6,5.7 \%$, being teased, being hit by other kids). The most frequent worries of children with BAIA were about harm $(n=15,14.3 \%)$, social threats $(n=11,10.5 \%)$, separation from parents $(n=6,5.7 \%)$, and being punished $(n=6,5.7 \%)$. Only one gender difference appeared with respect to the content of fears and worries of children with BAIA. More specifically, girls were more often scared of imaginary creatures than boys $\left[\chi^{2}(1)=6.8, P<0.01\right]$.

3.1.1.2. Normal children Percentages of normal children with fears and worries were 73.3 and $60.2 \%$, respectively. Tables 4 and 5 display the rank orders of their fears and worries. The most frequent fears pertained to animals $(n=39,22.2 \%)$, environmental threats $(n=18,10.2 \%$, e.g., water, thunderstorms, the dark), and personal harm $(n=17,9.7 \%)$. The most common worries of normal children had to do with social threats $(n=30,17.0 \%)$, personal harm $(n=26,14.8 \%)$, and medical affairs $(n=8,4.5 \%)$. Again, few gender differences were evident. Compared to boys, girls were more often scared of animals $\left[\chi^{2}(1)=5.4, P<0.05\right]$, they were less frequently afraid of personal harm $\left[\chi^{2}(1)=9.4, P<0.005\right]$, and worried less about frightening movies $\left[\chi^{2}(1)=5.8, P<0.05\right]$.

\subsubsection{Severity of fears and worries}

3.1.2.1. Children with BAIA Severity scores for fears and worries in this group were 2.3 $(\mathrm{SD}=0.6)$ and $2.0(\mathrm{SD}=0.7)$, respectively. This indicates that these anxiety phenomena were accompanied by moderate levels of anxiety.

3.1.2.2. Normal children Highly similar severity ratings of fears and worries were obtained in normal children, means being $2.4(\mathrm{SD}=0.6)$ and $2.0(\mathrm{SD}=0.6)$, respectively

Table 4

Rank order of specific fears reported by normal children (anxiety interview)

\begin{tabular}{|c|c|c|c|c|c|c|}
\hline & \multicolumn{2}{|c|}{ Total group $(n=176)$} & \multicolumn{2}{|c|}{ Boys $(n=83)$} & \multicolumn{2}{|c|}{ Girls $(n=93)$} \\
\hline & Frequency & $\%$ & Frequency & $\%$ & Frequency & $\%$ \\
\hline \multicolumn{7}{|l|}{ Fear } \\
\hline 1. Animals & 39 & 22.2 & 12 & 14.5 & 27 & $29.0^{\mathrm{a}}$ \\
\hline 2. Environmental threats & 18 & 10.2 & 7 & 8.4 & 11 & 11.8 \\
\hline 3. Personal harm or harm to others & 17 & 9.7 & 14 & 16.9 & 3 & $3.2^{\mathrm{a}}$ \\
\hline 4. Imaginary creatures & 12 & 6.8 & 3 & 3.6 & 9 & 9.7 \\
\hline 5. Social threats & 9 & 5.1 & 5 & 7.2 & 4 & 4.3 \\
\hline Frightening movies & 9 & 5.1 & 4 & 4.8 & 5 & 5.4 \\
\hline Burglar & 9 & 5.1 & 6 & 7.2 & 3 & 3.2 \\
\hline 6. Separation from parents & 6 & 3.4 & 1 & 1.2 & 5 & 5.4 \\
\hline 7. Being kidnapped & 5 & 2.8 & 1 & 1.2 & 4 & 4.3 \\
\hline 8. School performance & 2 & 1.1 & 2 & 2.4 & 0 & 0.0 \\
\hline 9. Medical affairs & 1 & 0.6 & 0 & 0.0 & 1 & 1.1 \\
\hline Death & 1 & 0.6 & 0 & 0.0 & 1 & 1.1 \\
\hline Being punished & 1 & 0.6 & 1 & 1.2 & 0 & 0.0 \\
\hline
\end{tabular}

a Difference between boys and girls significant at $P<0.05$. 
Table 5

Rank order of worries reported by normal children (anxiety interview)

\begin{tabular}{lcccccc}
\hline & \multicolumn{2}{c}{ Total group $(n=176)$} & Boys $(n=83)$ & \multicolumn{2}{c}{ Girls $(n=93)$} \\
\cline { 2 - 6 } & Frequency & $\%$ & Frequency & $\%$ & Frequency & \\
\hline Worry & & & & & & \\
1. Social threats & 30 & 17.0 & 14 & 16.9 & 16 & 17.2 \\
2. Personal harm or harm to others & 26 & 14.8 & 9 & 10.8 & 17 & 18.3 \\
3. Medical affairs & 8 & 4.5 & 2 & 2.4 & 6 & 6.5 \\
4. Being punished & 7 & 4.0 & 5 & 6.0 & 2 & 2.2 \\
Death & 7 & 4.0 & 3 & 3.6 & 4 & 4.3 \\
5. School performance & 6 & 3.4 & 3 & 3.6 & 3 & 3.2 \\
6. Frightening movies & 5 & 2.8 & 5 & 6.0 & 0 & $0.0^{\mathrm{a}}$ \\
Environmental threats & 5 & 2.8 & 3 & 3.6 & 2 & 2.2 \\
7. Separation from parents & 4 & 2.3 & 2 & 2.4 & 2 & 2.2 \\
8. Animals & 3 & 1.7 & 0 & 0.0 & 3 & 3.2 \\
9. Imaginary creatures & 2 & 1.1 & 1 & 1.2 & 1 & 1.1 \\
$\quad$ Little things & 2 & 1.1 & 1 & 1.2 & 1 & 1.1 \\
10. Divorce of parents & 1 & 0.6 & 1 & 1.2 & 0 & 0.0 \\
\hline
\end{tabular}

a Difference between boys and girls significant at $P<0.05$.

\subsubsection{Developmental patterns of fear and worry}

To examine developmental patterns, children with BAIA and normal children were divided into three age groups:

1. children aged $4-7$ years ( $n=24$ and $n=64$, respectively);

2. children aged $8-10$ years ( $n=44$ and $n=70$, respectively); and

3 . children aged $11-13$ years ( $n=37$ and $n=42$, respectively).

These age groups were primarily based on Piaget's theory of cognitive development in normal children. According to this theory, normal children aged 7 or younger are still in the preoperational stage (i.e., age group 1). From age 7 onwards, children would acquire concrete operational skills and hence would be increasingly able to solve conservation problems. To examine whether the anxiety phenomena change during the concrete operational phase, older children were further divided in two age groups (i.e., age groups 2 and 3; cf supra). The sample of children with BAIA was also broken into these three age groups, although it is clear that these children displayed a slowed cognitive development. In passing, it should be noted that the results of the conservation task were largely in keeping with Piagetian notions. More specifically, in normal children, $4.7 \%$ of the 4-7-year-olds, $75.7 \%$ of the $8-10$-year-olds, and $81.0 \%$ of the $11-13$-year-olds passed the conservation task $\left[\chi^{2}(2)=87.1, P<0.001\right]$. Statistical comparisons revealed a significant increase in successful conservation task performance from age group 1 to age group $2\left[\chi^{2}(1)=69.3\right.$, $P<0.001]$. In the group of children with BAIA, percentages of children who passed the conservation task were $4.2 \%$ for the $4-7$-year-olds, $22.7 \%$ for the $8-10$-year-olds, and $40.5 \%$ for the $11-13$-year olds $\left[\chi^{2}(2)=10.5, P<0.01\right]$. Thus, an increasing proportion of the children with BAIA in age groups $2\left[\chi^{2}(1)=3.9, P<0.05\right]$ and $3\left[\chi^{2}(1)=10.0, P<0.005\right]$ were able to solve the task, 
although percentages were still well below those found in the group of normal children [8-10year-olds: $\chi^{2}(1)=30.7, P<0.001 ; 11-13$-year-olds: $\left.\chi^{2}(1)=13.6, P<0.001\right]$.

3.1.3.1. Children with BAIA $\chi^{2}$ tests were carried out to compare the prevalence of fears and worries across the three age groups. As shown in the upper panel of Table 6 , the prevalence of fears was found to be relatively stable among children with BAIA [percentages were $45.8 \%$ among 4-7-year-olds, 52.3\% among 8-10-year-olds, and 54.1\% among 11 -13-year-olds; $\chi^{2}(2)=0.4$, $P=0.81]$. Worries were relatively uncommon among 4-6-year-old children with BAIA $(20.8 \%)$, became more prevalent among $8-10$-year-olds $(56.8 \%)$, and then remained relatively stable among $11-13$-year-olds $(59.5 \%)\left[\chi^{2}(2)=10.3, P<0.01\right]$. Note also that within the group of children with BAIA, girls more frequently reported fears than did boys $\left[\chi^{2}(1)=6.7, P<0.05\right]$ and this was particularly true for $8-10$-year-olds $\left[\chi^{2}(1)=3.7, P=0.05\right]$.

The upper panel of Table 7 displays the top intense fears and worries of children with BAIA. As can be seen, the top intense fears remained relatively stable across age levels. That is, fears of animals, harm, and social affairs and worries about harm, separation, and social affairs featured in the top three across all age groups.

3.1.3.2. Normal children The developmental patterns of fears and worries in normal children were highly similar to those reported in our previous study (Muris et al., 2000a). More specifically, fears were evident in more than half of the 4-7-year-olds, became highly prevalent in 8-10year-olds, and then returned to initial levels among $11-13$-year-olds $\left[\chi^{2}(2)=9.3, P<0.01\right]$. Worry displayed a somewhat different developmental course. The frequency of this anxiety phenomenon was found to increase gradually across the three age levels $\left[\chi^{2}(2)=5.2, P<0.10\right]$ (see lower panel of Table 6). Only one significant gender difference emerged: among 11-13-year-olds, girls more frequently reported fears than did boys $\left[\chi^{2}(1)=4.1, P<0.05\right]$.

Inspection of the top intense fears and worries of normal children revealed few differences across the various age groups. That is, fears typically pertained to animals and harm, whereas worries were concerned with harm and social affairs (Table 7).

Table 6

Prevalence rates (percentages) of fears and worries for children with BAIA and normal children broken down by the three age groups (anxiety interview) ${ }^{\mathrm{a}}$

\begin{tabular}{lllllllll}
\hline \multicolumn{7}{c}{ Age groups (years) } \\
\cline { 2 - 7 } & \multicolumn{1}{l}{ Total (boys/girls) } & $4-7$ (boys/girls) & $8-10$ (boys/girls) & $11-13$ (boys/girls) \\
\hline $\begin{array}{l}\text { Children with BAIA } \\
\quad \text { Fears }\end{array}$ & 51.4 & $(41.5 / 67.5)^{*}$ & 45.8 & $(37.5 / 62.5)$ & 52.3 & $(40.7 / 70.6)^{*} 54.1$ & $(45.5 / 66.7)$ \\
$\quad$ Worries & 49.5 & $(47.7 / 52.5)$ & $20.8 a$ & $(18.8 / 25.0)$ & $56.8 b$ & $(55.6 / 58.8)$ & $59.5 b$ & $(59.1 / 60.0)$ \\
Normal children & & & & & & & & \\
$\quad$ Fears & 73.3 & $(67.5 / 78.5)$ & $60.9 a$ & $(60.0 / 62.1)$ & $84.3 b$ & $(81.3 / 86.8)$ & $73.8 a, b$ & $(56.3 / 84.6)^{*}$ \\
$\quad$ Worries & 60.2 & $(59.0 / 61.3)$ & $51.6 a$ & $(54.3 / 48.3)$ & $60.0 a, b$ & $(59.4 / 60.5)$ & $73.8 b$ & $(68.8 / 76.9)$ \\
\hline
\end{tabular}

a Notes. $n=105$ for children with BAIA, $n=176$ for normal children. Within each row, group percentages with different italic letters differ at $P<0.05$ ( $\chi^{2}$ comparisons).

* Significant gender difference at $P<0.05$. 
Table 7

Top intense fears and worries of children with BAIA and normal children for each age group (anxiety interview)

\begin{tabular}{|c|c|c|c|}
\hline & \multicolumn{3}{|l|}{ Age groups (years) } \\
\hline & $4-7$ & $8-10$ & $11-13$ \\
\hline \multicolumn{4}{|c|}{ Children with BAIA } \\
\hline \multirow[t]{3}{*}{ Fears } & 1. Animals & 1. Animals & 1. Animals \\
\hline & 2. Imaginary creatures & 2. Social threats & 2. Personal harm/harm others \\
\hline & 3. Personal harm/harm others & 3. Personal harm/harm others & 3. Social threats \\
\hline \multirow[t]{3}{*}{ Worries } & 1. Personal harm/harm others & 1. Personal harm/harm others & 1. Social threats \\
\hline & 2. Separation from parents & 2. Social threats & 2. Being punished \\
\hline & Imaginary creatures & 3. Separation from parents & 3. Personal harm/harm others \\
\hline \multicolumn{4}{|c|}{ Normal children } \\
\hline \multirow[t]{3}{*}{ Fears } & 1. Environmental threats & 1. Animals & 1. Animals \\
\hline & 2. Imaginary creatures & 2. Burglar & 2. Personal harm/harm others \\
\hline & $\begin{array}{l}\text { 3. Animals } \\
\text { Frightening movies }\end{array}$ & 3. Personal harm/harm others & 3. Separation from parents \\
\hline \multirow[t]{3}{*}{ Worries } & 1. Personal harm/harm others & 1. Social threats & 1. Social threats \\
\hline & 2. Social threats & 2. Personal harm/harm others & 2. Personal harm/harm others \\
\hline & 3. Frightening movies & 3. Death & 3. Being punished \\
\hline
\end{tabular}

\subsection{Standardized self-report of anxiety: the $K F Q$}

\subsubsection{Children with BAIA}

Table 8 presents mean KFQ total scores of children with BAIA and the 10 most frequently endorsed fear items in this group. Two conclusions can be drawn from this table. First, girls generally reported higher fear levels than boys $[F(1,99)=29.9, P<0.001]$. In line with this, the majority of the top 10 fear items were more frequently endorsed by girls than by boys (e.g., burglar, being hit by a car, war, crocodiles, child molester, fire, and spiders). Second, a significant effect of age groups was found for the KFQ total score $[F(2,99)=4.7, P<0.05]$. That is, fears were found to decrease gradually with age (e.g., lions, crocodiles, fire, and spiders).

\subsubsection{Normal children}

Mean KFQ scores of normal children are displayed in Table 9. As can be seen, a significant gender effect emerged $[F(1,170)=14.8, P<0.001]$ with girls displaying higher anxiety levels than boys. Furthermore, a significant effect of age groups was found $[F(2,170)=12.1, P<0.001]$ such that fear scores declined when age increased.

\subsection{Relationship between anxiety interview and $K F Q$}

The connection between data obtained with the Anxiety Interview and KFQ scores was examined by means of point-biserial correlations (while controlling for age and gender). Results showed that only the presence of fear as indexed by the interview was moderately associated with $\mathrm{KFQ}$ scores $[r(105)=0.42, P<0.001$ in children with BAIA; $r(176)=0.30, P<0.001$ in normal children]. 
Table 8

Mean KFQ total score (standard deviation) of children with BAIA and the 10 most frequently endorsed items (percentage of children rating 'very scared') ${ }^{\mathrm{a}}$

\begin{tabular}{|c|c|c|c|c|c|c|}
\hline & \multirow{2}{*}{$\begin{array}{l}\text { Total } \\
(n=105)\end{array}$} & \multirow{2}{*}{$\begin{array}{l}\text { Boys } \\
(n=65)\end{array}$} & \multirow{2}{*}{$\begin{array}{l}\text { Girls } \\
(n=40)\end{array}$} & \multicolumn{3}{|c|}{ Age groups (years) } \\
\hline & & & & $4-7(n=24)$ & $8-10(n=44)$ & $11-13(n=37)$ \\
\hline Total score & $53.9(13.0)$ & $49.2(12.1)$ & $\begin{array}{l}61.5 \\
(10.9)^{*}\end{array}$ & $58.2(13.5) a$ & $54.5(13.1) a, b$ & $50.4(12.1) b$ \\
\hline 1. Getting lost & 57.1 & 50.8 & 67.5 & 70.8 & 56.8 & 48.6 \\
\hline 2. Burglar & 56.2 & 36.9 & $87.5^{*}$ & 58.3 & 56.8 & 54.1 \\
\hline 3. Being hit by a car & 55.2 & 46.2 & $70.0^{*}$ & 66.7 & 54.5 & 48.6 \\
\hline 4. The death & 52.4 & 47.7 & 60.0 & 58.3 & 50.0 & 51.4 \\
\hline 5. War & 49.5 & 32.3 & $77.5^{*}$ & 45.8 & 59.1 & 40.5 \\
\hline 6. Lions & 47.6 & 43.1 & 55.0 & $62.5 a$ & $52.3 a, b$ & $32.4 b$ \\
\hline 7. Crocodiles & 43.8 & 33.8 & $60.0^{*}$ & $66.7 a$ & $45.5 a, b$ & $27.0 b$ \\
\hline 8. Child molester & 41.0 & 26.2 & $65.0^{*}$ & 45.8 & 43.2 & 35.1 \\
\hline 9. Fire & 38.1 & 29.2 & $52.5^{*}$ & $66.7 a$ & $40.9 a$ & $16.2 b$ \\
\hline 10. Spiders & 38.1 & 27.7 & $55.0^{*}$ & $58.3 a$ & $36.4 a, b$ & $27.0 b$ \\
\hline
\end{tabular}

${ }^{a}$ Notes. KFQ=Koala Fear Questionnaire. Percentages/means with different italic letters differ at $P<0.05\left(\chi^{2}\right.$ and t-tests).

* Significant gender difference at $P<0.05$.

Table 9

Mean KFQ total score (standard deviation) of normal children and the 10 most frequently endorsed items (percentage of children rating 'very scared') ${ }^{\mathrm{a}}$

\begin{tabular}{|c|c|c|c|c|c|c|}
\hline & \multirow{2}{*}{$\begin{array}{l}\text { Total } \\
(n=176)\end{array}$} & \multirow{2}{*}{$\begin{array}{l}\text { Boys } \\
(n=83)\end{array}$} & \multirow{2}{*}{$\begin{array}{l}\text { Girls } \\
(n=93)\end{array}$} & \multicolumn{3}{|c|}{ Age groups (years) } \\
\hline & & & & $4-7(n=64)$ & $8-10(n=70)$ & $11-13(n=42)$ \\
\hline Total score & $57.6(9.7)$ & $55.1(8.4)$ & $\begin{array}{l}59.8 \\
(10.3)^{*}\end{array}$ & $60.6(9.3) a$ & $57.9(9.1) a$ & $52.5(10.0) b$ \\
\hline 1. Getting lost & 73.9 & 78.3 & 69.9 & 73.4 & 77.1 & 69.0 \\
\hline 2. Being hit by a car & 67.6 & 65.1 & 69.9 & $76.6 a$ & $68.6 a, b$ & $52.4 b$ \\
\hline 3. War & 65.9 & 67.5 & 64.5 & 67.2 & 72.9 & 52.4 \\
\hline 4. Burglar & 53.4 & 49.4 & 57.0 & 59.4 & 55.7 & 40.5 \\
\hline 5. The death & 50.6 & 45.8 & 54.8 & 56.3 & 54.3 & 35.7 \\
\hline 6. Child molester & 50.6 & 43.4 & 57.0 & 57.8 & 50.0 & 40.5 \\
\hline 7. Fire & 50.6 & 53.0 & 48.4 & $67.2 a$ & $51.4 a$ & $23.8 b$ \\
\hline 8. Parents divorcing & 48.9 & 44.6 & 52.7 & 53.1 & 50.0 & 40.5 \\
\hline 9. Lions & 47.2 & 44.6 & 49.5 & $53.1 a$ & $51.4 a$ & $31.0 b$ \\
\hline 10. Crocodiles & 43.2 & 41.0 & 45.2 & $62.5 a$ & $41.4 b$ & $16.7 c$ \\
\hline
\end{tabular}

${ }^{a}$ Notes. KFQ=Koala Fear Questionnaire. Percentages/means with different subscripts differ at $P<0.05\left(\chi^{2}\right.$ and $t$ tests).

* Significant gender difference at $P<0.05$. 
In other words, children who indicated during the interview that fear was present displayed higher KFQ scores than children who reported no fear.

\subsection{Comparisons of children with BAIA and normal children}

\subsubsection{Fears and worries as assessed by the anxiety interview}

3.4.1.1. Prevalence As mentioned earlier, children with BAIA and normal children differed considerably with regard to a number of demographic variables (i.e., gender, age, socio-economic background, and family structure). Therefore, prevalence rates of anxiety phenomena in children with BAIA and normal children were compared through regression analyses in which demographic variables were entered in the equations at step 1. A logistic regression analyses with fear $(0=$ absent, $1=$ present $)$ as criterion variable, showed that group status $(1=$ children with BAIA, $2=$ normal children) accounted for a significant proportion of the variance $[\beta=0.86, \mathrm{SE}=0.34$, Wald $\left.\chi^{2}(1)=6.3, P<0.05\right]$. In a logistic regression analysis with worry as criterion, group status explained a marginally significant proportion of the variance $\left[\beta=0.57, \mathrm{SE}=0.33\right.$, Wald $\chi^{2}(1)=3.0$, $P<0.10]$. In both cases, the positive betas indicate that normal children more frequently reported fears and worries than children with BAIA (see Table 6).

\subsubsection{Content}

Tables 2-5 and Table 7 show that there were no substantial differences with respect to content of specific fears and worries in children with BAIA and normal children.

3.4.2.1. Severity Regression analyses (in which demographic variables were entered at step 1) with group status as the predictor and severity ratings of fears and worries as criterion, revealed no significant effects. Thus, in both children with BAIA and normal children, fears and worries had similar severity levels.

3.4.2.2. Developmental patterns As can be seen in Table 6, developmental patterns of fears and worries were quite different. To examine differences in the prevalence rates between children with BAIA and normal children across the various age groups, a series of logistic regression analyses (in which demographic variables were entered at step 1) was carried out with group status as the predictor and occurrence of anxiety phenomena for each age level as criterion. These analyses revealed significant contributions of group status to fears $[\beta=1.89, \mathrm{SE}=0.76$, Wald $\left.\chi^{2}(1)=6.1, P<0.05\right]$ and worries $\left[\beta=2.34, \mathrm{SE}=0.80\right.$, Wald $\left.\chi^{2}(1)=8.6, P<0.005\right]$ among 4-7-yearolds. In both cases, the positive betas indicate that among the younger children, fears and worries were more prevalent in the normal group than in the group of children with BAIA.

\subsubsection{Fears as indexed by the $K F Q$}

To compare KFQ scores of children with BAIA and normal children, a linear regression analysis (in which demographic variables were entered at step 1) was performed with group status as predictor and KFQ scores as criterion. Results showed no significant effect of group status. In other words, no differences in KFQ scores between children with BAIA and normal children were found. 
As can be seen in Tables 8 and 9, there were no large differences between children with BAIA and normal children as to the content of the 10 most frequently endorsed items.

\subsection{Relationship between level of cognitive development and the experience of fear and worry}

\subsubsection{Fears and worries as assessed by means of the anxiety interview}

3.5.1.1. Children with BAIA To examine the relationship between cognitive development and the experience of fear and worry, a series of logistic regression analyses (while controlling for gender at step 1) was conducted with performance on the conservation task as predictor and occurrence of anxiety phenomena as criterion. For children with BAIA, conservation task performance did not account for a significant proportion of the variance of fears and worries as indexed by the Anxiety Interview.

3.5.1.2. Normal children For normal children, logistic regression analyses showed significant contributions of conservation task performance to the occurrence of fears $[\beta=0.81, \mathrm{SE}=0.35$, Wald $\left.\chi^{2}(1)=5.3, P<0.05\right]$, worries $\left[\beta=0.55, \mathrm{SE}=0.31\right.$, Wald $\left.\chi^{2}(1)=3.1, P<0.10\right]$, or both anxiety phenomena $\left[\beta=0.70, \mathrm{SE}=0.31\right.$, Wald $\left.\chi^{2}(1)=5.1, P<0.05\right]$. In all cases, positive betas indicate that fears and worries were more common among children who successfully passed the conservation task. To illustrate, Fig. 1 displays percentages of children with 0 , 1, or both anxiety phenomena who successfully solved the conservation problem. As can be seen, percentages of normal children who passed the conservation task nicely covaried with the prevalence of anxiety phenomena. No such linear association was evident for children with BAIA.

\subsubsection{Fears as indexed by the $K F Q$}

Children with BAIA. A linear regression analysis with gender entering on step 1, conservation task performance as predictor and KAQ total score as criterion, showed that conservation task performance accounted for a siginificant proportion of the variance $[\beta=-7.49, \mathrm{SE}=2.54, t=-2.9$, $P<0.005]$. The negative beta indicates that fear scores were significantly lower in children with BAIA who passed the conservation task than in those who failed this task.

3.5.2.1. Normal children A similar analysis performed on the data of normal children also revealed that conservation task performance explained a significant proportion of the variance of

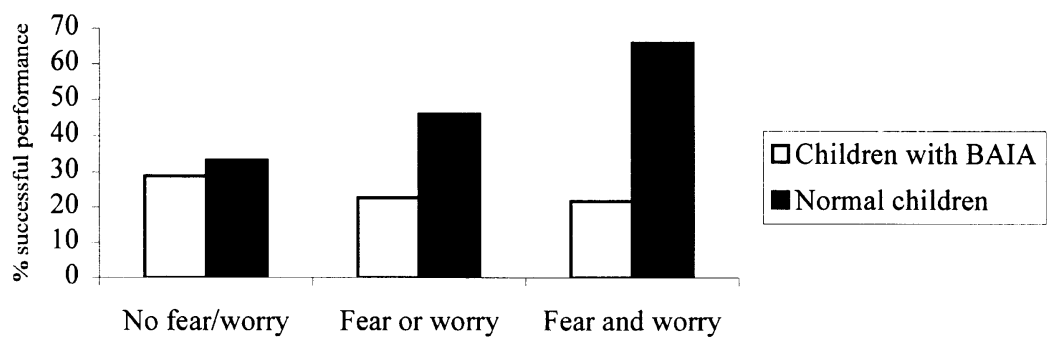

Fig. 1. Percentages of children with no fear/worry, children with either fear or worry, or children with both fear and worry who passed the conservation test. 
KFQ scores $[\beta=-5.10, \mathrm{SE}=1.38, t=-3.7, P<0.001]$. Again, the negative beta implies that fear scores were lower in normal children who successfully solved the conservation task.

\section{Discussion}

The present study examined the relationship between cognitive capacity and children's fears and worries. To address this issue, fears and worries of normal children were compared to those of children with BAIA. Furthermore, we explored whether level of cognitive development as indexed by a Piagetian conservation task was associated with frequency and intensity of fears and worries.

As to the link between cognitive maturation, on the one hand, and fears and worries, on the other hand, a number of inconsistencies were found that had to do with the different measures that we used to document anxiety phenomena. Thus, for children's fears and worries as assessed by means of the Anxiety Interview, some evidence was found to suggest that greater cognitive capacity promotes the frequency of these anxiety phenomena. More specifically, normal children more frequently reported fears and worries than children with BAIA. Furthermore, in normal children, support was found for the idea that fears and worries were more prevalent among children with higher levels of cognitive development. However, for fear levels as measured by the KFQ, there were no significant differences between children with BAIA and normal children. Moreover, in both children with BAIA and normal children, data suggested that fears as indexed by the KFQ were less frequent in children with higher levels of cognitive development.

How can these conflicting results be reconciled? In this respect it is important to note that the Anxiety Interview and the KFQ seem to tap quite different aspects of anxiety. This is most clearly illustrated by the rather modest associations between fear as indexed by the interview and KFQ scores ( $r$ s between 0.30 and 0.42 ). Furthermore, inspection of the top intense fears (and worries) as obtained by both instruments (see Tables 2-5 and Tables 8 and 9) reveals some remarkable differences. While some items list high in both fear rankings, there are also a number of items that figure high in one rank order, but low in the other one (e.g., social threats, war). This comes as no surprise because previous studies clearly showed that children's fear rank orders critically depend on the assessment method that is used (see Muris et al., 1997a,b). A related point is that the current study found fears and worries as assessed by the Anxiety Interview to become more prevalent with increasing age, while fears as indexed by the KFQ decreased as children grew older. This pattern of results makes sense when one bears in mind that the KFQ capitalizes on early childhood fears, whereas the Anxiety Interview is not biased in that direction as it uses a free format. Early childhood fears largely originate from unfamiliarity with stimuli and such unfamiliarity gradually decreases during cognitive development (Hebb, 1946). In contrast, the more subtle anxiety phenomena (e.g., worry) that do not figure prominently in the KFQ require a certain level of cognitive maturation and, thus, covary with age.

Despite some differences in prevalence rates of fears and worries, the content of these anxiety phenomena was highly similar for children with BAIA and normal children. This result can best be interpreted in terms Marks' (1987) ontogenetic parade of fears. Briefly, this parade refers to the predictable pattern of normal fears and worries that emerge, plateau, and decline in the course of children's development. The similarities in content of fears and worries reported by children 
with BAIA and normal children deserve some further comment. First of all, our analysis of the content of fears and worries was rather crude. That is, content was only defined in terms of global categories of situations and stimuli. Analysis of fears and worries in terms of complexity, variety, elaboration, and feared consequences (see Vasey et al., 1994) might have provided a more detailed picture of the content of these anxiety phenomena. Second, the present study mainly focused on the prevalence rather than the pathological quality of fears and worries. Recent studies by Muris et al. (1998a) and Muris, Merckelbach, Mayer, and Prins (2000c) (see also Muris \& Merckelbach, 2000a) show that fears and worries reflect significant anxiety disorders in a nontrivial minority of children. Most importantly, these studies found that similar fears and worries may be manifestations of a variety of anxiety disorders (see also Muris, Merckelbach, Mayer, \& Meesters, 1998b). For example, 'fear of death' may pertain to specific phobia (blood-injection-injury type), generalized anxiety disorder, or separation anxiety disorder. Thus, content in terms of a global category may represent quite different types of anxiety.

The results we obtained for the sample of normal children are by and large in line with those of previous studies (see for a comprehensive review, Muris \& Merckelbach, 2000b). For example, the fears and worries rank orders as obtained by the Anxiety Interview closely parallel those reported in earlier 'free option' surveys of these anxiety phenomena (Muris et al., 1998a; Muris et al., 2000a,c), whereas the fears rank order obtained with the KFQ comes close to that reported in previous research relying on the Fear Survey Schedule for Children (e.g., Ollendick et al. 1989, 1991; Muris et al., 1997b). Furthermore, the current data replicate the well-established developmental patterns of fear and worry (e.g., Marks, 1987). For instance, in accordance with Bauer's (1976) findings, 'early' fears about imaginary creatures and predators were found to decrease as children grew older. Like previous studies (see Muris et al., 2000a,c), anxiety phenomena in general and worry in particular were found to be especially prevalent during middle childhood. Finally, previous studies have consistently noted that girls generally display higher levels of fear, worry, and anxiety than boys (see Bernstein \& Borchardt, 1991; Craske, 1997). In line with this, the present study found that girls had higher fear scores on the KFQ than boys. The Anxiety Interview revealed only a few robust gender effects, but here too, girls generally displayed higher frequencies of anxiety phenomena than did boys.

In normal children, a significant association between cognitive maturation as indexed by a Piagetian conservation task and fears and worries as measured by the Anxiety Interview was observed, such that successful performance on the conservation task was linked to higher anxiety levels. Interestingly, this connection did not show up in the group of children with BAIA. The most obvious reason is that relatively few of these children (i.e., only $24.8 \%$ ) passed the conservation task.

The present study was subject to several limitations that deserve some comments. One limitation is that our study solely relied on children's self-reports of fears and worries. While the use of a structured interview (i.e., the Anxiety Interview) in combination with a standardized self-report scale (i.e., the KFQ) is certainly a strength of this study, obtaining information from children's parents might have provided more precise data as to the content, prevalence, and developmental patterns of anxiety phenomena. A second limitation is that our study was cross-sectional in nature. Plainly, a longitudinal set-up in which children are followed for several years, would provide a more detailed picture of the developmental course of anxiety (see Ollendick \& King, 1994). Most importantly, such an approach would make it possible to determine whether cognitive maturation serves as an antecedent of more 'cognitive' anxiety symptoms such as worry. 
A third limitation of the present study is that we employed a single and typically Piagetian conservation task to measure children's cognitive maturation. Meanwhile, researchers have criticized Piaget's view on cognitive development. For example, Gelman (1972) noted that when Piagetian tasks are sufficiently well explained and simplified, even 4-5-year-old children are able to solve conservation problems. Other authors (for a comprehensive critique of Piaget's conservation tasks, see Kail, 1998) have pointed out that repeated questioning about the amount of liquid may give children the idea that their previous answer was wrong, and hence that this procedure influences children's reaction to the crucial question. On the basis of these observations, one could question the current study's operationalization of children's cognitive capacity by means of a conservation task (e.g., Halford, 1989). On the other hand, the present data provide some indirect evidence for the validity of the conservation task in that there was a marked increase in the percentage of normal children who successfully solved the task after the age of 7. Additionally, although the number of children with BAIA who passed the task increased with age, percentages of successful performance in this group were considerably lower than those in normal children.

A fourth and final shortcoming of our study has to do with the statistical comparisons that were made between children with BAIA and normal children. Although we controlled for a number of demographic variables (e.g., family structure, socio-economic status), comparing anxiety and fear measures of these two groups of children might be affected by a number of other variables (e.g., a higher prevalence of behavioural or social problems in children with BAIA).

Several authors have proposed that anxiety phenomena such as fears and worries are mediated by children's level of cognitive development (see e.g., Ollendick et al., 1991; Vasey, 1993). The current study was a preliminary attempt to investigate this issue. Notwithstanding the limitations of this study, our data seem to suggest that cognitive development, indeed, modulates childhood anxiety phenomena. Reduced cognitive capacity seems to promote 'early' fears, whereas increased cognitive maturation is likely to enhance more complex anxiety phenomena such as worry.

\section{References}

American Psychiatric Association (1994). Diagnostic and statistical manual of mental disorders. (4th ed.). Washington, DC: American Psychiatric Association.

Bauer, D. H. (1976). An exploratory study of developmental changes in children's fears. Journal of Child Psychology and Psychiatry, 17, 69-74.

Bernstein, G. A., \& Borchardt, C. (1991). Anxiety disorders of childhood and adolescence: A critical review. Journal of the American Academy of Child and Adolescent Psychiatry, 30, 519-532.

Bleichrodt, N., Drenth, P. J. D., Zaal, J. N., \& Resing, W. C. M. (1987). Revisie Amsterdamse Kinder Intelligentie Test - Handleiding. [Revision Amsterdam Child Intelligence Test - Manual] Lisse: Swets and Zietlinger.

Borkovec, T. D., Robinson, E., Pruzinsky, T., \& DePree, J. A. (1983). Preliminary explanation of worry: Some characteristics and processes. Behaviour Research and Therapy, 21, 9-16.

Cole, M., \& Cole, S. R. (1996). The development of children. New York: Freeman and company.

Craske, M. G. (1997). Fear and anxiety in children and adolescents. Bulletin of the Menninger Clinic, 61, 4-34.

Gelman, R. (1972). Logical capacity of very young children: Number invariance rules. Child Development, 43, 75-90.

Gullone, E., \& King, N. J. (1992). Psychometric evaluation of a revised fear survey schedule for children and adolescents. Journal of Child Psychology and Psychiatry, 33, 987-998.

Gullone, E., King, N. J., \& Cummins, R. A. (1996). Fears of youth with mental retardation: Psychometric evaluation of the Fear Survey Schedule for Children - II (FSSC-II). Research in Developmental Disabilities, 17, 269-284. 
Halford, G. S. (1989). Reflections on 25 years of Piagetian cognitive developmental psychology: 1963-1988. Human Development, 32, 325-357.

Hebb, D. O. (1946). On the nature of fear. Psychological Review, 35, 259-276.

Kail, R. V. (1998). Children and their development. New Jersey: Prentice Hall.

Lentz, K. (1985). Fears and worries of young children as expressed in a contextual play setting. Journal of Child Psychology and Psychiatry, 26, 981-987.

Marks, I. M. (1987). Fear, phobias, and rituals. Panic, anxiety, and their disorders. New York: Oxford University Press.

Marks, I. M., \& Nesse, R. M. (1994). Fear and fitness: A evolutionary analysis of anxiety disorders. Ethology and Sociobiology, 15, 247-261.

Muris, P., Meesters, C., \& Mayer, B. (2000b). The Koala Fear Questionnaire: A standardized, pictorial scale for measuring fears in young children. Maastricht: Maastricht University.

Muris, P., Meesters, C., Merckelbach, H., Sermon, A., \& Zwakhalen, S. (1998a). Worry in normal children. Journal of the American Academy of Child and Adolescent Psychiatry, 37, 703-710.

Muris, P., \& Merckelbach, H. (2000a). How serious are common childhood fears? II. The parents' point of view. Behaviour Research and Therapy, 38, 813-818.

Muris, P., \& Merckelbach, H. (2000b). The etiology of childhood specific phobias: A multifactorial model. In M. W. Vasey, \& M. Dadds, The developmental psychopathology of anxiety (pp. 764-832). New York: Oxford University Press.

Muris, P., Merckelbach, H., \& Collaris, R. (1997a). Common childhood fears and their origins. Behaviour Research and Therapy, 35, 929-937.

Muris, P., Merckelbach, H., Gadet, B., \& Moulaert, V. (2000a). Fears, worries, and scary dreams in 4- to 12-year-old children: Their content, developmental pattern, and origins. Journal of Clinical Child Psychology, 29, 43-52.

Muris, P., Merckelbach, H., Mayer, B., \& Meesters, C. (1998b). Common fears and their relationship to anxiety disorders symptomatology in normal children. Personality and Individual Differences, 24, 575-578.

Muris, P., Merckelbach, H., Mayer, B., \& Prins, E. (2000c). How serious are common childhood fears? Behaviour Research and Therapy, 38, 217-228.

Muris, P., Merckelbach, H., Meesters, C., \& Van Lier, P. (1997b). What do children fear mot often? Journal of Behavior Therapy and Experimental Psychiatry, 28, 263-267.

Ollendick, T. H. (1983). Reliability and validity of the Revised Fear Survey Schedule for Children (FSSC-R). Behaviour Research and Therapy, 21, 685-692.

Ollendick, T. H., \& King, N. J. (1994). Diagnosis, assessment, and treatment of internalizing problems in children: The role of longitudinal data. Journal of Consulting and Clinical Psychology, 62, 918-927.

Ollendick, T. H., King, N. J., \& Frary, R. B. (1989). Fears in children and adolescents: Reliability and generalizability across gender, age, and nationality. Behaviour Research and Therapy, 27, 19-26.

Ollendick, T. H., Yang, B., King, N. J., Dong, Q., \& Akande, A. (1996). Fears in American, Australian, Chinese, and Nigerian children and adolescents: A cross-cultural study. Journal of Child Psychology and Psychiatry, 37, 213-220.

Ollendick, T. H., Yule, W., \& Ollier, K. (1991). Fears in British children and their relationship to manifest anxiety and depression. Journal of Child Psychology and Psychiatry, 32, 321-331.

Orton, G. L. (1982). A comparative study of children's worries. Journal of Psychology, 110, 153-162.

Piaget, J. (1970). Self-reported fears in children with and without mental retardation. In P. H. Mussen, Carmichaels's manual of child psychology (Vol. I) (pp. 703-732). New York: Wiley.

Ramirez, S. Z., \& Kratochwill, T. R. (1997). Self-reported fears in children with and without mental retardation. Mental retardation, 35, 83-92.

Schroots, J. J., \& Alphen de Veer, R. J. (1976). LDT, Leidse Diagnostic Test, Deel 1 Handleiding (LDT, Leiden Diagnostic Test, Part 1 Manual). Amsterdam: Swets and Zeitlinger.

Shore, G. N., \& Rapport, M. D. (1998). The Fear Survey Schedule for Children - Revised (FSSC-HI): Ethnocultural variations in children's fearfulness. Journal of Anxiety Disorders, 12, 437-461.

Silverman, W. K., La Greca, A. M., \& Wasserstein, S. (1995). What do children worry about? Worries and their relation to anxiety. Child Development, 66, 671-686.

Spielberger, C. D. (1973). Manual for the state-trait anxiety inventory for children. Palo Alto, CA: Consulting Psychologists Press. 
Stevenson-Hinde, J., \& Shouldice, A. (1995). 4.5 to 7 years: Fearful behaviour, fears and worries. Journal of Child Psychology and Psychiatry, 36, 1027-1038.

Stickler, G. B. (1996). Worries of parents and their children. Clinical Pediatrics, 35, 84-90.

Toren, H., Stilma, L. C., Menkveld, H., Kievit, T., Redmeijer, S. J., Lafeber, C., \& Bolkestein, G. (1978). Niet alle kinderen gaan naar de basisschool. [Not all children go to normal primary school] Nijkerk: Intro.

Vasey, M. W. (1993). Development and cognition in childhood anxiety: The example of worry. Advances in Clinical Child Psychology, 15, 1-39.

Vasey, M. W., Crnic, K. A., \& Carter, W. G. (1994). Worry in childhood: A developmental perspective. Cognitive Therapy and Research, 18, 529-549.

Vasey, M. W., \& Daleiden, E. L. (1994). Worry in children. In G. C. L. Davey, \& F. Tallis, Worrying: Perspectives on theory, assessment, and treatment (pp. 185-207). Chichester: Wiley.

Vandenberg, B. (1993). Fears in normal and mentally retarded children. Psychological Reports, 72, 473-474.

Wechsler, D. (1974). Wechsler Intelligence Scale for children - revised. New York: Psychological Corporation.

Wechsler, D. (1989). Wechsler Intelligence Scale for children - revised. San Antonio: Psychological Corporation. 